\title{
Efeitos do treinamento físico sobre a força muscular em paraplégicos
}

\author{
Effects of the physical treatment about the muscular power in paraplegic \\ Ligia Franciele Bortolloti ${ }^{1}$, Heloisa Freiria Tsukamoto ${ }^{2}$
}

\section{RESUMO}

Objetivo. Verificar os efeitos do treinamento físico com membros superiores (MMSS) na força muscular (FM) de paraplégicos. Método. Participaram sete paraplégicos (seis homens) com idade média de $40,28 \pm 15,9$ anos. Utilizou-se, no início e fim do tratamento, o Teste de Uma Repetição Máxima (1RM) e a manovacuometria, para avaliar a FM dos MMSS e dos músculos respiratórios, respectivamente. A capacidade funcional foi dada pela Medida de Independência Funcional (MIF). O treinamento físico foi realizado três vezes por semana, num total de 20 sessóes. O protocolo de tratamento consistia de exercícios de aquecimento, alongamentos e fortalecimento muscular, realizado com $70 \%$ de 1 RM nas 10 primeiras sessóes, e $90 \%$ nas últimas. Ao final, uma entrevista para avaliar a satisfaçáo dos pacientes em relação ao treinamento proposto foi aplicada. A análise estatística foi realizada pelos testes Kolmogorov-Smirnov e Wilcoxon, adotando $\mathrm{p}<0,05$. Resultados. Houve ganho significante de FM dos MMSS direito e esquerdo ao final do treinamento $(\mathrm{p}=0,018$ e $\mathrm{p}=0,017$ respectivamente) e todos os participantes relataram maior facilidade em realizar suas atividades cotidianas. A manovacuometria não mostrou diferença significativa. Conclusáo. O período de sete semanas de treinamento foi suficiente para promover ganhos significantes na FM de paraplégicos, facilitando o desempenho de suas atividades diárias.

Unitermos. Traumatismos da Medula Espinal, Paraplegia, Força Muscular.

Citaçáo. Bortolloti LF, Tsukamoto HF. Efeitos do treinamento físico sobre a força muscular em paraplégicos.

\begin{abstract}
Objective. To investigate the effects of physical training with the upper limbs (ULs) in muscle strength (MS) of paraplegic patients. Method. Participated in seven paraplegic patients (six men) with mean age of $40.28 \pm 15.9$ years. It was used at the beginning and end of treatment, the Maximum Repetition Test (1RM) and manometer to assess the MS upper limb and respiratory muscles, respectively. Functional capacity was provided by the Functional Independence Measure (FIM). Physical training was performed three times per week, totaling 20 sessions. The treatment protocol consisted of warm-up exercises, stretching and strengthening exercises, done with $70 \%$ of $1 \mathrm{RM}$ in the first 10 sessions, and $90 \%$ in the past. Finally, a interview to assess patients' satisfaction in relation to the proposed training was applied. Statistical analysis was performed by Kolmogorov-Smirnov and Wilcoxon tests, considering $\mathrm{p}<0.05$. Results. There was a significant gain in MS right and left upper limb at the end of training $(\mathrm{p}=0.018$ and $\mathrm{p}=0.017$ respectively) and all participants reported greater ease in performing daily activities. The manometer showed no significant difference. Conclusion. The period of seven weeks of training was sufficient to promote significant gains in MS paraplegic, facilitating the performance of their daily activities.
\end{abstract}

Keywords. Spinal Cord Injuries, Paraplegia. Muscle Strength.

Citation. Bortolloti LF, Tsukamoto HF. Effects of the physical treatment about the muscular power in paraplegic.
Trabalho realizado na Faculdade de Apucarana - FAP, Apucarana-PR, Brasil. 1. Graduanda em Fisioterapia pela Faculdade de Apucarana - FAP, ApucaranaPR, Brasil.

2. Fisioterapeuta, Especialista em Fisioterapia Neurofuncional Adulto pelo HURNPR/UEL, Docente do curso de Fisioterapia da Faculdade de Apucarana - FAP, Apucarana-PR, Brasil.
Endereço para correspondência:

Heloísa F Tsukamoto

Rua Andirá, 195, Jardim Kowalski CEP 86020-520, Londrina-PR, Brasil.

E-mail: heloisaft@hotmail.com

Relato de Caso Recebido em: 27/01/10 Aceito em: 06/07/10 Conflito de interesses: nấo 


\section{INTRODUÇÃO}

O número crescente de acidentes com veículos automotores, associado ao aumento da violência nas áreas urbanas, tem elevado a incidência de traumas na população geral. Ao atingir a coluna vertebral, estes traumas podem resultar numa lesão irreversível da medula espinhal e suas raízes nervosas, danificando a função motora e sensorial do indivíduo ${ }^{1}$.

A lesão medular de origem traumática altera de maneira drástica o curso de vida, levando à consequências sociais e econômicas para o paciente, a família e a sociedade ${ }^{2}$.

Tetraplegia e paraplegia são termos usados para descrever os indivíduos portadores de lesão medular e indicam a dimensão da perda funcional. Assim, o termo paraplegia refere-se à diminuição ou perda da função motora e/ou sensitiva dos segmentos torácicos, lombares ou sacrais da medula espinhal, secundários a danos dos elementos neurais dentro do canal vertebral. Deixa íntegros os membros superiores e, dependendo do nível, pode acometer a função do tronco, membros inferiores e órgãos pélvicos ${ }^{3}$.

Com os avanços ocorridos na medicina nas últimas décadas, houve um consequente aumento na sobrevida de pacientes lesados medulares. Com isso, o tratamento fisioterapêutico passou a objetivar a maximização da independência funcional do indivíduo e sua reintegração na sociedade, devendo incluir a prevenção de deformidades e complicações, incremento da função muscular remanescente e da função respiratória, treino de transferências e trocas de posturas, manuseio da cadeira de rodas, treino de equilíbrio, aquisição de ortostatismo e possível retorno da marcha com uso ou não de dispositivos ortóticos ${ }^{4}$.

Após a lesão, força e resistência dos músculos das extremidades superiores são importantes para o indivíduo paraplégico durante a propulsão da cadeira de rodas e para o desempenho das atividades diárias, como deitar e levantar da cama, entrar e sair do carro, ir ao banheiro, trocar de roupa, dentre outros 5 .

Desta forma, o fortalecimento muscular tornase imprescindível ao processo de reabilitação do lesado medular, pois a independência funcional está sujeita ao preparo de toda a musculatura preservada ${ }^{6}$.

A força muscular é considerada como um impor- tante componente da aptidáo física relacionada à saúde, sendo que dentre as diferentes formas de treinamento para o seu desenvolvimento, destaca-se a prática de exercícios com pesos ${ }^{7}$.

Durante a avaliação, o teste de Uma Repetição Máxima (1RM) é frequentemente usado para medir a força muscular, e operacionalmente é definido como a maior carga que pode ser movida por uma amplitude específica de movimento, uma única vez e com execução correta. Esse teste é o principal método para aferir a força de um indivíduo e, consiste basicamente em encontrar a carga máxima que um indivíduo é capaz de utilizar ao completar uma única repetição de determinado exercício ${ }^{8,9}$.

O teste de 1RM pode ser utilizado antes e após um treinamento, como forma de monitorar as variações possivelmente relacionadas ao protocolo de treino aplicado e, também, para estabelecer uma padronização na intensidade da carga a ser utilizada durante uma investigação, sendo que nesse caso, um dado percentual do resultado do teste é utilizado na realização do treinamento?

As principais vantagens da utilizaçáo de testes de 1RM estão relacionadas à facilidade para interpretação das informaçóes produzidas, ao baixo custo operacional e à possibilidade de aplicação em populações com níveis de aptidão física bastante diferenciados ${ }^{10}$.

Sabe-se que o grau de independência funcional do paciente lesado medular, durante suas atividades de vida diária, está diretamente relacionado com o seu nível neurológico. Maior esforço físico e maior gasto energético são necessários quanto mais alto for o nível da lesão, durante a realizaçáo de atividades como transferências, propulsão da cadeira de rodas e transposição de barreiras arquitetônicas e ambientais 5 .

Verifica-se, portanto, a necessidade de implantar um Programa de Treinamento Físico para indivíduos lesados medulares, visto que os mesmos beneficiam-se com esta prática, obtendo, além de melhor capacidade física, aumento nos índices de independência funcional e nas atividades de vida diária, menor predisposição ao risco de doenças cardiovasculares, e melhoras também no convívio social, bem-estar psicológico e qualidade de vida ${ }^{11}$.

Este estudo teve como objetivo verificar os efeitos do treinamento físico com membros superiores (MMSS) sobre a força muscular (FM) residual de paraplégicos após 
Lesão Medular (LM), e sua interferência no desempenho de suas atividades diárias.

\section{MÉTODO}

Trata-se de um estudo exploratório descritivo com abordagem quantitativa, caracterizando-se como uma pesquisa quase-experimental. As atividades foram realizadas na cidade de Apucarana - PR, nas dependências da Clínica Escola de Fisioterapia da Faculdade de Apucarana (FAP), "Dra. Sônia Gusman", no período de junho a agosto de 2009.

\section{Amostra}

Para atender aos objetivos da pesquisa, foi composta uma amostra intencional, sendo incluídos no estudo sete pacientes que se enquadraram nos seguintes critérios: ter idade acima de 18 anos e diagnóstico clínico de LM, apresentando quadro de paraplegia, tendo a cadeira de rodas como seu principal meio de locomoção. Foram excluídos indivíduos que apresentavam déficit motor devido a outras patologias neurológicas, complicaçóes osteomioarticulares que impediam a realização das atividades propostas, doenças pulmonares prévias, hipertensão arterial mal controlada, assim como os que realizavam atividades físicas envolvendo fortalecimento muscular de MMSS fora do ambiente terapêutico (por exemplo, em academias).

Todos os participantes foram informados sobre o conteúdo da pesquisa e, após estarem de acordo, assinaram o Termo de Consentimento Livre e Esclarecido. A pesquisa foi submetida à análise do Comitê de Ética na Pesquisa em Seres Humanos da Faculdade de Apucarana (FAP), CETi-FAP, seguindo normas da Resolução 196/96 do CNS/MS, e obteve emissão de parecer com aprovação, no222/2009.

\section{Procedimentos e intervençáo terapêutica}

Após a triagem, os pacientes foram convidados a comparecer à Clínica Escola de Fisioterapia da FAP, em data e horário previamente agendado, onde foi realizada uma avaliação inicial, com a aplicação dos seguintes instrumentos: uma ficha de identificação do participante do estudo, contendo informaçóes a respeito dos dados pessoais, anamnese e sinais vitais; a Standard Neurological
Classification of Spinal Cord Injury ${ }^{12}$, usada para avaliar pacientes lesados medulares de forma padronizada, a fim de identificar o tipo de lesão da medula espinhal (completa ou incompleta) e os níveis neurológico, motor e sensitivo; e a Medida da Independência Funcional (MIF), para medir o grau de capacidade funcional dos indivíduos. Validada no Brasil em 2004, a MIF é um instrumento genérico de avaliação da incapacidade de pacientes com restriçóes funcionais de origem variada, que tem como objetivo avaliar, de forma quantitativa, a carga de cuidados demandada por uma pessoa para a realização de uma série de tarefas motoras e cognitivas de vida diária ${ }^{13}$.

Para mensurar a força muscular (FM) de membros superiores (MMSS) nos paraplégicos, foi utilizado o Teste de Uma Repetição Máxima (1RM) com o membro superior (MS) dominante, a fim de determinar a carga máxima que o indivíduo era capaz de mover na amplitude completa de um movimento padrão, executando uma única vez. Este teste foi realizado seguindo um protocolo de pesquisa ${ }^{14}$, com o paciente sentado em sua própria cadeira de rodas, onde inicialmente era realizado aquecimento durante cinco minutos num aparelho cicloergômetro adaptado para MMSS (CAJUMORO ${ }^{\circ}$ ), com carga leve e velocidade média de 65 rotaçôes por minuto, seguido por uma série de alongamentos ativos e passivos dos músculos da regiâo cervical e de MMSS, mantendo cada posicionamento por 30 segundos. Em seguida, o paciente recebeu instruçóes sobre o movimento padrão escolhido para o teste e posterior treinamento físico com pesos, baseado na técnica de Facilitaçấo Neuromuscular Proprioceptiva - Método Kabat ${ }^{15}$, sendo utilizada a chamada segunda diagonal para MMSS, realizada com uso de halteres e caneleiras (de 0,5 a $5 \mathrm{Kg}$ ). O MS partiu da postura de extensão, adução e rotação interna de ombro, extensão de cotovelo, pronação de antebraço, extensão de punho e flexão dos dedos, com o membro à frente do tronco, e seguiu para a postura de flexão, abdução e rotação externa de ombro e supinação de antebraço, com manutenção da posição do cotovelo, punho e dedos. Antes do teste, o paciente pôde familiarizar-se com o movimento padrão, realizando oito repetiçóes com cerca de $50 \%$ da carga estimada para 1RM. Logo após, um intervalo de dois minutos foi realizado.

Durante a execução do teste de 1RM, solicitou-se 
ao paciente que realizasse duas repetiçôes na amplitude total do movimento padrão, e sem compensaçóes, como inclinar ou hiperestender o tronco, ou segurar-se no assento da cadeira com o MS contralateral. Caso fossem completadas as duas repetiçóes, era realizado um intervalo de três minutos e a carga era aumentada (em 0,5 Kg). Caso não fosse completada nenhuma repetição, também era realizado um intervalo de três minutos e a carga era diminuída (em $0,5 \mathrm{Kg})$. O procedimento foi repetido até que o indivíduo realizasse uma única repetição máxima do movimento padrão, ou seja, até que fosse encontrada a carga máxima com a qual o indivíduo era capaz de realizar o movimento solicitado.

Para quantificar a força muscular respiratória, através das medidas da Pressão Inspiratória Máxima (PImáx) e da Pressão Expiratória Máxima (PEmáx), foi usada a Manovacuometria. O aparelho utilizado foi o Manovacuômetro (MAKIL ${ }^{\oplus}$ ), com escala operacional em $\mathrm{cmH}_{2} \mathrm{O}$, que permite mensuraçóes entre $-200 \mathrm{a}+200$ $\mathrm{cmH}_{2} \mathrm{O}$. A medida foi executada com o paciente sentado em sua própria cadeira de rodas, com o tronco ereto e $90^{\circ}$ de flexão de quadril e joelho. Para obter a PImáx, o paciente realizava uma expiração forçada máxima (volume residual), e a seguir um esforço inspiratório estático máximo durante três segundos, com a via aérea ocluída por um clipe nasal. Similarmente, para obter a PEmáx, solicitou-se ao paciente que realizasse uma inspiração forçada máxima (capacidade pulmonar total) e a seguir um esforço expiratório estático máximo durante três segundos, com oclusão nasal e labial evitando escape aéreo. Para cada paciente, um total de cinco medidas foram executadas, sendo considerada a medida de melhor valor ${ }^{16}$. Para o cálculo do valor predito para os pacientes do gênero masculino foi utilizada a fórmula PImáx $=(-0,80 \mathrm{x}$ idade) $+155,3-17,3$ para a força muscular inspiratória e PEmáx $=(-0,81 \mathrm{x}$ idade $)+165,3-15,6$ para a força muscular expiratória. Para a paciente do gênero feminino foi utilizada a fórmula PImáx $=(-0,49 \mathrm{x}$ idade $)+110,4-9,1$ e PEmáx $=(-0,61 \mathrm{x}$ idade $)+115,6-11,2$ para medida da força muscular inspiratória e expiratória, respectivamente.

Ao término das avaliações iniciais, os pacientes foram submetidos a um Programa de Treinamento Físico, com frequência de três vezes semanais realizadas em dias alternados com intervalo de 48 a 72 horas entre cada ses- são, duração de 40 minutos cada terapia, totalizando 20 sessões, num período de sete semanas. Todos os pacientes foram instruídos a não realizar exercícios físicos com os MMSS fora do ambiente terapêutico, durante a sua participação no estudo, para não interferir nos resultados.

O protocolo de treinamento físico foi realizado com o paciente sentado em sua própria cadeira de rodas, e consistia de: 1) aquecimento durante cinco minutos, usando um aparelho cicloergômetro portátil adaptado para MMSS, com carga leve e velocidade de 65 rotaçóes por minuto; 2) alongamentos ativos e passivos dos músculos da regiáo cervical e de MMSS, mantidos por 30 segundos, com duas repetições, com duração aproximada de cinco minutos; 3) treinamento da musculatura, para familiarização com o movimento padrão, em uma série de 15 repetiçóes com $50 \%$ da carga a ser trabalhada no treinamento com pesos, seguida de um intervalo de 60 a 90 segundos. Assim, era iniciado o 4) treinamento com pesos, realizado utilizando-se $70 \%$ da carga determinada no teste de $1 \mathrm{RM}$ para cada paciente, durante as 10 primeiras sessóes. Nas 10 sessóes seguintes, a carga foi reajustada para $90 \%$ de 1 RM. Foi estabelecido um total de três séries de oito a doze repetiçóes do movimento, durante as 20 sessóes, com intervalo de 60 a 90 segundos de repouso entre cada série. A pressão arterial foi aferida no início e fim de cada sessão de treinamento.

Ao término das 20 sessóes, cada participante foi reavaliado, através da realização do Teste de 1RM, para verificar ganhos na FM de MMSS; e da Manovacuometria, para medir a PImáx e PEmáx. No Teste de 1RM, a carga inicial foi a que estava sendo utilizada durante o treinamento.

E, por fim, uma ficha de perguntas foi elaborada pelos autores e aplicada a fim de avaliar, subjetivamente, a satisfação dos pacientes com relação ao treinamento proposto. Esta ficha constou de três questóes, na forma de entrevista estruturada: Questão 1 - "Houve melhora nas suas atividades diárias como diminuição do cansaço para impulsionar a cadeira de rodas, transferir-se, tomar banho e vestir-se, comparativamente ao período anterior ao treinamento?"; Questão 2 - "Qual o seu grau de satisfação, em relação ao seu bem-estar físico, após o Programa de Treinamento Físico, comparativamente ao período anterior ao treinamento?”; e Questão 3 - "Qual o seu grau de satisfação, em relação ao seu bem-estar psicológico, após 
o Programa de Treinamento Físico, comparativamente ao período anterior ao treinamento?”.

\section{Análise estatística}

Os dados coletados nas avaliaçóes iniciais e finais foram tabulados e analisados estatisticamente através do Programa SPSS 13.0 for Windows. Para verificar a normalidade dos dados, utilizou-se o teste de KolmogorovSmirnov e, para a comparaçáo dos dados o teste de Wilcoxon, adotando nível de significância de 5\% (p<0,05).

\section{RESULTADOS}

Participaram do estudo sete indivíduos com diagnóstico de paraplegia por LM, com idade média de $40,28 \pm 15,9$ anos. Seis dos participantes eram do gênero masculino e apenas uma do gênero feminino. A Tabela 1 mostra as características da população estudada.

$\mathrm{Na}$ análise do grau de incapacidade funcional dos pacientes, a média da pontuação da MIF total foi de $104,42 \pm 13,8$ pontos. A função cognitiva, medida pela MIF cognitiva, obteve valores máximos para todos os indivíduos (35 pontos). Já a função motora apresentou-se comprometida em todos os pacientes, sendo que o valor da média da MIF motora foi de 69,42 $\pm 13,8$ pontos. A atividade na qual todos os pacientes relataram grande dificuldade foi subir e descer escadas (um ponto). Nas de- mais, apenas três pacientes apresentaram pontuaçóes menor ou igual a três pontos (P2, P4 e P7). Nos domínios banho, asseio, controle vesical, controle anal, banheiro, banheira/chuveiro e caminhar/cadeira de rodas, a pontuação máxima foi de seis pontos, significando independência modificada (uso de aparelho/adaptação). Estes dados são mostrados na Tabela 2.

Todos os participantes do estudo apresentaram aumento no valor da carga usada no Teste de 1RM após o treinamento físico com pesos, o que representa ganho de força muscular de MMSS. Este incremento de força muscular foi significante $(\mathrm{p}<0,05)$. A média de $1 \mathrm{RM}$ do membro superior direito (MSD) na avaliação inicial foi de 4,0 kg $\pm 2,43$ e aumentou, na avaliação final, para 6,92 $\mathrm{kg} \pm 2,87$, com $\mathrm{p}=0,018$. No membro superior esquerdo (MSE), a média de 1RM na avaliação inicial foi de 3,92 $\mathrm{kg} \pm 2,49$ e aumentou, na avaliação final, para $6,78 \mathrm{~kg} \pm$ $2,82, \operatorname{com} \mathrm{p}=0,017$.

Os valores de 1RM do MSD e do MSE e as porcentagens de incremento da carga usada nas avaliaçóes pré e pós-treinamento físico com pesos estão ilustrados nas Tabelas 3 e 4, respectivamente.

Em relação à medida da força muscular respiratória, não houve diferença significante entre os valores do início e fim do tratamento, para a força muscular inspiratória (PImáx, $\mathrm{p}=0,86$ ) e para a força muscular expiratória

Tabela 1

Caracterização da população do estudo

\begin{tabular}{|c|c|c|c|c|c|c|}
\hline Paciente & Gênero & $\begin{array}{l}\text { Idade } \\
\text { (anos) }\end{array}$ & $\begin{array}{l}\text { Etiologia da } \\
\text { lesáo }\end{array}$ & $\begin{array}{l}\text { Tempo de lesáo } \\
\text { (anos) }\end{array}$ & $\begin{array}{c}\text { Nível } \\
\text { neurológico }\end{array}$ & $\begin{array}{l}\text { Classificaçáo } \\
\text { da lesão - ASIA }\end{array}$ \\
\hline P1 & M & 36 & $\begin{array}{l}\text { ferimento por } \\
\text { arma de fogo }\end{array}$ & 1 & L2 & B \\
\hline P2 & F & 28 & $\begin{array}{l}\text { acidente } \\
\text { automobilístico }\end{array}$ & 1 & $\mathrm{~T} 5$ & A \\
\hline P3 & M & 43 & $\begin{array}{l}\text { ferimento por } \\
\text { arma de fogo }\end{array}$ & 10 & L3 & B \\
\hline $\mathrm{P} 4$ & M & 28 & $\begin{array}{c}\text { acidente } \\
\text { automobilístico }\end{array}$ & 14 & T6 & A \\
\hline P5 & M & 23 & $\begin{array}{l}\text { acidente } \\
\text { automobilístico }\end{array}$ & 5 & T6 & A \\
\hline P6 & M & 52 & $\begin{array}{l}\text { queda de objeto } \\
\text { sobre a coluna }\end{array}$ & 11 & T8 & A \\
\hline P7 & M & 71 & $\begin{array}{l}\text { queda de plano } \\
\text { elevado }\end{array}$ & 22 & T11 & A \\
\hline
\end{tabular}

ASIA A - Lesão medular completa;

ASIA B - Lesão medular incompleta (alguma sensibilidade preservada abaixo do nível neurológico). 
(PEmáx, $\mathrm{p}=0$,497). Observou-se um decréscimo no valor da média da PImáx na reavaliação, assim como uma diminuição nos valores da PImáx e PEmáx de alguns pacientes, na análise individual. Os valores pré e pós-treinamento estáo ilustrados na Tabela 5.

Quando questionados sobre melhoras nas suas atividades de vida diária, como impulsionar a cadeira de rodas, tomar banho e vestir-se, todos os pacientes relataram melhora e, também, que sentem-se menos cansados para realizar as atividades do dia-a-dia, em comparação ao período anterior ao treinamento, além de melhoras também em seu bem-estar psicológico.

\section{DISCUSSÃO}

Para o indivíduo portador de lesão medular, reabilitar-se significa passar pelo processo que busca o desenvolvimento das suas capacidades remanescentes, permitindo o alcance de independência nas atividades físicas, profissionais e sociais, de acordo com seu nível de lesão. Durante a reabilitaçâo, através da fisioterapia, é possível prevenir o surgimento de complicaçôes clínicas e, especialmente, alcançar a capacidade funcional máxima do paciente lesado medular ${ }^{17}$.

Neste estudo, pôde-se observar que o período de sete semanas de treinamento regular foi suficiente para promover ganho de força muscular de membros superio- res para os pacientes treinados. A intensidade do treinamento e o número de séries e de repetições utilizadas, foram determinadas de acordo com os dados encontrados na literatura científica.

Para indivíduos iniciantes e intermediários é recomendado o treinamento com carga correspondente entre 60-70\% de 1RM, de 1-3 séries cada exercício e frequência de 2 a 3 vezes semanais. Para indivíduos em nível avançado, o treinamento é recomendado com carga de 80-100\% de 1RM para maximizar a força muscular (nível de evidência $A$ ), com frequência de 3 a 4 vezes na semana para indivíduos em nível intermediário (nível de evidência B), e de 4 a 6 vezes semanais para indivíduos avançados (nível de evidência $\mathrm{C})^{18}$.

O fortalecimento muscular responde melhor de dois a quatro dias de treinamento por semana em indivíduos saudáveis. Para promover aumento de força é indicada uma intensidade de resistência que permita a realização de 8 a 12 repetiçóes. Uma maior intensidade de exercício (maior peso e menor número de repetiçóes) aumenta a taxa de ganho muscular ${ }^{19}$.

Frequentemente se observa nas clínicas de fisioterapia certa resistência por parte dos pacientes paraplégicos em realizar os exercícios de fortalecimento muscular durante a terapia. Queixas de cansaço, "preguiça”, dores, entre outras, são relatadas pelos pacientes na tentativa de

Tabela 2

Valores dos domínios na MIF motora na avaliação inicial

\begin{tabular}{cccccccccc}
\hline MIF motora & P1 & P2 & P3 & P4 & P5 & P6 & P7 & Média \\
\hline Alimentaçáo & 7 & 7 & 7 & 7 & 7 & 7 & 7 & 7,00 \\
Cuidados com a aparência & 7 & 7 & 7 & 7 & 7 & 7 & 7 & 7,00 \\
Banho & 6 & 3 & 6 & 3 & 6 & 6 & 1 & 4,42 \\
Vestir parte superior do corpo & 7 & 7 & 7 & 7 & 7 & 7 & 7 & 7,00 \\
Vestir parte inferior do corpo & 7 & 7 & 7 & 7 & 7 & 7 & 1 & 5,14 \\
Asseio & 6 & 6 & 6 & 6 & 6 & 6 & 6 & 6,00 \\
Controle vesical & 6 & 6 & 6 & 6 & 6 & 6 & 1 & 5,28 \\
Controle esfincter anal & 6 & 6 & 6 & 1 & 6 & 6 & 1 & 4,57 \\
Cama, cadeira, cadeira de rodas & 7 & 3 & 7 & 7 & 7 & 7 & 1 & 5,57 \\
Banheiro & 6 & 1 & 6 & 6 & 6 & 6 & 1 & 4,57 \\
Banheira, chuveiro & 6 & 3 & 6 & 6 & 6 & 6 & 1 & 4,85 \\
Caminhar, cadeira de rodas & 6 & 6 & 6 & 6 & 6 & 6 & 6 & 6,00 \\
Escada & 1 & 1 & 1 & 1 & 1 & 1 & 1 & 1,00 \\
\hline Total & 78 & 63 & 78 & 70 & 78 & 78 & 41 & 69,42 \\
\hline
\end{tabular}


não realizar estes exercícios. E, quando o executam, muitas vezes não o fazem de forma correta, respeitando a carga, o número de séries e repetiçốes. Tem-se a ideia de que já foi atingido o grau máximo de força muscular possível.

Através da avaliação do nível motor dos pacientes, realizada pela prova de função muscular, com resistência manual, constatou-se que todos os participantes apresentavam grau cinco nos MMSS. Nesta avaliação de força muscular, a graduação é feita com valores de zero a cinco, onde zero significa ausência de contração muscular e cinco, força muscular normal vencendo grande resistência manual $^{20}$.

Tabela 3

Valores de $1 R M(\mathrm{Kg})$ do $M S D$, pré e pós-treinamento físico

\begin{tabular}{cccc}
\hline Paciente & $\begin{array}{c}\text { Teste de 1RM } \\
\text { inicial MSD } \mathbf{( K g})\end{array}$ & $\begin{array}{c}\text { Teste de 1RM } \\
\text { final MSD } \mathbf{( K g})\end{array}$ & $\begin{array}{c}\text { \% de incremento } \\
\text { da carga }\end{array}$ \\
\hline P1 & 8,5 & 12,0 & $41,1 \%$ \\
P2 & 0,5 & 3,5 & $600 \%$ \\
P3 & 4,5 & 7,0 & $55,5 \%$ \\
P4 & 4,0 & 7,0 & $75,0 \%$ \\
P5 & 3,5 & 5,5 & $57,1 \%$ \\
P6 & 4,5 & 9,0 & $100 \%$ \\
P7 & 2,5 & 4,5 & $80 \%$ \\
Média & 4,0 & 6,92 & $73 \%$ \\
\hline
\end{tabular}

Tabela 4

Valores de $1 R M(K g)$ do MSE, pré e pós-treinamento físico

\begin{tabular}{cccc}
\hline Paciente & $\begin{array}{c}\text { Teste de 1RM } \\
\text { inicial MSE }(\mathbf{K g})\end{array}$ & $\begin{array}{c}\text { Teste de 1RM } \\
\text { final MSE }(\mathbf{K g})\end{array}$ & $\begin{array}{c}\text { \% de incremento } \\
\text { da carga }\end{array}$ \\
\hline P1 & 8,5 & 12,0 & $41,1 \%$ \\
P2 & 0,5 & 3,5 & $600 \%$ \\
P3 & 4,5 & 7,0 & $55,5 \%$ \\
P4 & 4,0 & 7,0 & $75,0 \%$ \\
P5 & 3,5 & 6,0 & $71,4 \%$ \\
P6 & 4,5 & 8,0 & $77,7 \%$ \\
P7 & 2,0 & 4,0 & $100 \%$ \\
Média & 3,92 & 6,78 & $72,9 \%$ \\
\hline
\end{tabular}

Tabela 5

Avaliação da força muscular respiratória pré e pós treinamento físico

\begin{tabular}{ccccc}
\hline Paciente & $\begin{array}{c}\text { PI máx inicial } \\
\left(\mathbf{c m H}_{\mathbf{2}} \mathbf{0}\right)\end{array}$ & $\begin{array}{c}\text { PI máx final } \\
\left(\mathbf{c m H}_{\mathbf{2}} \mathbf{0}\right)\end{array}$ & $\begin{array}{c}\text { PE máx inicial } \\
\left(\mathbf{c m H}_{\mathbf{2}} \mathbf{0}\right)\end{array}$ & $\begin{array}{c}\text { PE máx final } \\
\left(\mathbf{c m H}_{\mathbf{2}} \mathbf{0}\right)\end{array}$ \\
\hline P1 & -125 & -120 & 150 & 140 \\
P2 & -80 & -125 & 40 & 45 \\
P3 & -175 & -185 & 100 & 115 \\
P4 & -185 & -155 & 80 & 95 \\
P5 & -155 & -165 & 100 & 105 \\
P6 & -150 & -175 & 115 & 150 \\
P7 & -200 & -75 & 100 & 50 \\
Média & $-163,5$ & $-142,8$ & 97,8 & 100 \\
\hline
\end{tabular}


Assim, testes realizados por este método tornam a avaliação subjetiva, pois depende da opiniāo e da quantidade de força aplicada por cada avaliador. Além disso, torna-se difícil quantificar o ganho de força muscular, visto que a graduação do teste limita-se ao grau máximo de força muscular cinco. Portanto, um indivíduo que já está na graduação máxima cinco não conseguirá observar o quanto de força muscular foi adquirida com o treinamento.

Desta forma, o teste de 1RM surge como uma alternativa adequada para medir a força muscular em indivíduos paraplégicos, visto que se mostra como um teste simples e prático, capaz de quantificar o aumento da força muscular. E mais, ele se torna um incentivo ao participante, pois assim este consegue notar o ganho de força muscular conquistado cada vez que sua carga é aumentada, nas avaliações seguintes.

O teste de 1RM tem sido amplamente utilizado como padrão de referência para a avaliação da força muscular em diferentes populaçóes, uma vez que, com base nos resultados obtidos, é possível analisar o comportamento da força muscular em diferentes grupos musculares, avaliar a efetividade ou não de programas regulares de atividades físicas para o aumento da força muscular ou, ainda, prescrever a intensidade a ser aplicada em exercícios com pesos ${ }^{10}$.

Similarmente a este estudo, Nunciato ${ }^{21}$ avaliou a força muscular em um indivíduo lesado medular nível T11-T12, através do teste de $1 \mathrm{RM}$, e realizou um protocolo de treinamento de força e treinamento funcional durante oito semanas, verificando que houve aumento da força muscular dos MMSS no paciente, proporcionando discreta melhora na qualidade das transferências bem como nas suas atividades funcionais, traduzindo esse ganho em melhora na independência funcional do lesado medular.

O comprometimento funcional de indivíduos com lesão medular é amplamente variável conforme as características da lesão. Entre os participantes, foi possível observar que os que apresentaram baixas pontuaçóes na MIF eram portadores de lesão medular torácica alta (T5 ou T6) ou idade avançada (71 anos). Também Riberto ${ }^{13}$ relatou em seu estudo que entre os pacientes lesados medulares com maior comprometimento motor foi possível observar valores mais baixos de independência funcional.
A escala MIF, embora amplamente utilizada, apresenta baixa sensibilidade, ou seja, baixa responsividade quanto a ganhos sutis na independência funcional. Uma alternativa seria manter o uso desta escala, que é amplamente utilizada, e agregar itens que pudessem aumentar sua sensibilidade em determinadas situaçôes ${ }^{22}$.

Com relação à medida da força muscular respiratória, não foi observado um aumento significante nos seus valores e, por isto, não se pode afirmar que o treinamento de força de MMSS influencia na força muscular respiratória. Valores não condizentes com a capacidade pulmonar esperada para esta amostra puderam ser apurados, e isto ocorreu possivelmente por uma falha na realização do teste da manovacuometria. Faz-se necessário novos estudos para verificar se existe uma relação entre o treinamento de força de MMSS com o aumento da força muscular respiratória.

Ressalta-se que, apesar dos indivíduos terem recebido treinamento da manovacuometria antes do teste ser executado, eles demonstravam, ainda, bastante incompreensão no momento de sua realização. Todas as dúvidas em relação ao teste por parte dos pacientes foram sanadas pelas pesquisadoras. Porém, ainda assim, dificuldades na realização do mesmo puderam ser observadas, fato este que pode explicar a diminuição dos valores que alguns pacientes apresentaram na reavaliação, tanto na PImáx quanto na PEmáx. Por essas razóes não foi possível analisar a influência do fortalecimento muscular de membros superiores sobre a força muscular respiratória no presente estudo.

O envolvimento respiratório em lesados medulares pode ser evidenciado pela considerável diminuição da força muscular, medida pelas pressóes inspiratória e expiratória estáticas máximas. A redução dessas pressôes ocorre pela fraqueza ou paralisia muscular respiratória, bem como pela alteração da mecânica ventilatória. Neste sentido, podemos assegurar a importância da mensuração das pressóes respiratórias estáticas máximas na propedêutica dos pacientes portadores de lesão medular traumática ${ }^{23}$.

Machado relata que os músculos abdominais, como músculos respiratórios, têm ação predominantemente expiratória e sáo inervados pelos nervos torácicos de T7 a T12 e primeiro nervo lombar, sendo, portanto, invariavelmente mais afetados que os músculos inspiratórios, independentemente do nível da lesão medular ${ }^{24}$. Diante disso, o fato 
da análise da PEmáx não ter demonstrado um resultado estatisticamente significante pode ser explicado pela altura do nível motor de quatro indivíduos, que apresentaram nível torácico alto, demonstrando perda da atividade dos músculos abdominais devido a falta de inervação, provocada pela lesão medular.

Ao final do estudo, foi aplicada uma ficha de avaliação subjetiva da satisfação dos pacientes em relação ao treinamento proposto, sob a forma de entrevista, a fim de verificar melhoras na independência funcional, percebidas pelos próprios participantes. Todos eles relataram melhor desempenho das atividades diárias ao final do treinamento, respondendo "sim" às questôes propostas, demonstrando que o ganho de força muscular gera aumento na independência funcional do lesado medular. Abaixo, foram relatados alguns dos comentários feitos pelos participantes ao final do treinamento.

Paciente P1: "principalmente para me locomover na cadeira (de rodas), tocar a cadeira, subir rampinhas".

Paciente P2: "bem mais tranquilo para as atividades, bem melhor do que antes".

Paciente P3: "me sinto bem mais forte para fazer as coisas dentro de casa, as dores diminuiram,... antes precisava parar na rampa que tem perto de casa e depois continuar, agora vou e volto sem parar, não sinto a cadeira (de rodas) pesada".

Paciente P4: "melhorou muito, me sinto mais forte, bem menos cansado principalmente para puxar a cadeira (de rodas) e para as transferências".

Paciente P5: "me sinto mais forte, melhor, o exercício físico faz bem, ajuda bastante, dá mais disposição".

Paciente P6: "me sinto mais forte, não sinto mais dificuldade para transferir e empurrar a cadeira (de rodas), a cadeira está mais fácil de empurrar".

Paciente P7: "a cadeira (de rodas) ficou mais leve, subo a rampinha da minha casa bem mais fácil, ajudou bastante, me sinto mais forte, meu braço está maior".

Do ponto de vista funcional, os exercícios resistidos podem proporcionar importantes contribuiçôes no desempenho das atividades cotidianas, visto que todos os participantes relataram melhora em suas atividades do dia a dia que exigem força, referindo mais facilidade e menos cansaço para realização de tais atividades.
Observou-se ainda que, mesmo em casos de lesão crônica e antiga (22 anos de lesão) e idade avançada (71 anos), o treinamento de força trouxe resultados satisfatórios, refletindo esse ganho de força muscular em melhoras no bem-estar físico e psicológico do indivíduo.

Os benefícios do exercício resistido vão além das melhoras óbvias no desempenho muscular, pois inclui os efeitos positivos sobre o sistema cardiovascular, o tecido conjuntivo e ósseo, além disso, influenciam a função. Os indivíduos passam a realizar suas atividades diárias com mais facilidade porque estão funcionando com um menor percentual de sua capacidade máxima. Esse funcionamento melhorado pode aprimorar também a sensação de bem-estar e de independência do paciente ${ }^{25}$.

\section{CONCLUSÕES}

A Fisioterapia tem um importante papel na reabilitação do paciente lesado medular, pois tem muito a contribuir com a melhoria de suas capacidades funcionais, promovendo qualidade na vida desses indivíduos.

A aplicação de um protocolo de treinamento físico regular com pesos para pessoas com paraplegia e seus efeitos sobre a força muscular e atividades cotidianas diárias é relevante, se faz importante por contribuir com aplicabilidade clínica, simples e de baixo custo, e resulta em mudanças significantes no ganho de força muscular.

\section{REFERÊNCIAS}

1.Ninomya AF, Jesus CLM, Auletta LL, Rimkus CM, Ferreira DM, Zoppi Filho A, et al. Análise clínica e ultrassonográfica dos ombros de pacientes lesados medulares em programa de reabilitação. Acta Ortop Bras 2007;15:109-13. 2.Marotta JT. Lesōes medulares. In: Rowland LP. Merrit - tratado de neurologia. 10ed. Rio de Janeiro: Guanabara Koogan, 2002, p.362-8.

3.Barros Filho TEP, Oliveira RP, Kalil EM, Prada FS. Avaliação padronizada nos traumatismos raquimedulares. Rev Bras Ortop 1994;29:99-106.

4.Sartori J, Neuwald MF, Bastos VH, Silva JG, Mello MP, Freitas MRG, et al. Reabilitaçâo física na lesão traumática da medula espinhal: relato de caso. Rev Neuroc 2009;17:364-79.

5.Giacomini MCC. Trabalho resistido adaptado visando a independência de pessoas com paraplegia nas suas atividades de vida diária (Dissertaçáo). Campinas: Universidade Estadual de Campinas, 2007, 172p.

6.Maruyama DB, Soares DP. Tratamento fisioterápico na lesão medular. In: Greve JMD, Casalis MEP, Barros Filho TEP. Diagnóstico e tratamento da lesão da medula espinhal. São Paulo: Roca, 2001, p.93-114. 
7.Dias RMR, Cyrino ES, Salvador EP, Caldeira LFS, Nakamura FY, Papst RR, et al. Influência do processo de familiarização para avaliaçáo da força muscular em testes de 1RM. Rev Bras Med Esporte 2005;11:34-8.

http://dx.doi.org/10.1590/S1517-86922005000100004

8.Pereira MIR, Gomes PSC. Testes de força e resistência muscular: confiabilidade e predição de uma repetição máxima - revisão e novas evidências. Rev Bras Med Esporte 2003;9:325-35.

9.Barros MAP, Sperandei S, Silveira Júnior PCS, Oliveira CG. Reprodutibilidade no teste de uma repetiçáo máxima no exercício de puxada pela frente para homens. Ver Bras Med Esporte 2008;14:348-52.

http://dx.doi.org/10.1590/S1517-86922008000400005

10.Gurjāo ALD, Cyrino ES, Caldeira LFS, Nakamura FY, Oliveira AR, Salvador EP, et al. Variaçấo da força muscular em testes repetitivos de 1RM em crianças pré-púberes. Rev Bras Med Esporte 2005;11:319-24.

11.Silva MCR, Oliveira RJ, Conceição MIG. Efeitos da nataçấo sobre a independência funcional de pacientes com lesão medular. Rev Bras Med Esporte 2005;11:251-6.

12.Maynard FM, Bracken MB, Creasey G, Ditunno JF, Donovan WH, Ducker TB, et al. International standards for neurological and functional classification of spinal cord injury. Spinal Cord 1997;35:266-74.

http://dx.doi.org/10.1038/sj.sc.3100432

13.Riberto M, Miyazaki MH, Jucá SSH, Sakamoto H, Pinto PPN, Battistella LR. Validação da versão brasileira da Medida de Independência Funcional. Acta Fisiatr 2004;11:72-6.

14.Dias RMR, Cyrino ES, Salvador EP, Nakamura FY, Pina FLC, Oliveira AR. Impacto de oito semanas de treinamento com pesos sobre a força muscular de homens e mulheres. Rev Bras Med Esporte 2005;11:224-8.

http://dx.doi.org/10.1590/S1517-86922005000400004

15.Adler SS, Beckers D, Buck M. Membro superior. In: Adler SS, Beckers D, Buck M. PNF facilitaçấo neuromuscular proprioceptiva: um guia ilustrado. 2 ed. Barueri, São Paulo: Manole, 2007, p.93-154.
16.Souza RB. Diretrizes para testes de função pulmonar. J Bras Pneumol 2002;28:155-65.

17.Faria CDV, Moreira MCS, Barbosa MCC, Sabbag LMS. Utilizaçáo do suporte de peso corporal em solo no treino de marcha do lesado medular. Acta Fisiatr 2005;12:21-5.

18.American College of Sports Medicine. Position Stand: Progression models in resistance training for healthy adults. Medicine Science Sportes Exercise 2009; $41: 687-708$.

http://dx.doi.org/10.1249/MSS.0b013e3181915670

19.Dale RB, Harrelson GL, Leaver-Dunn D. Princípios da reabilitaçấo. In: Andrews JR, Harrelson GL, Wilk KE. Reabilitação física do atleta. Rio de Janeiro: Elsevier, 2008, p.163-95.

20.Kendall FP, McCreary EK, Provance PG. Músculos: provas e funçóes. 4 ed. São Paulo: Manole, 1995, 453p.

21.Nunciato AC, Pastrelo D, Leite RD, Prestes J, Medalha CC. Treinamento de força e treinamento funcional em adolescente lesado medular - relato de caso. ConScientiae Saúde 2009;8:281-8.

22.Barbetta DC, Assis MR. Reprodutibilidade, validade e responsividade da escala de Medida de Independência Funcional (MIF) na lesão medular: uma revisão de literatura. Acta Fisiatr 2008;15:176-81.

23. Mateus SRM. Determinação dos valores de referência das pressôes respiratórias estáticas máximas na lesão medular traumática (Tese). Brasília: Universidade de Brasília, 2006, 108p.

24.Machado MGR. Anatomia e funçấo dos músculos respiratórios. In: Machado MGR. Bases da fisioterapia respiratória: terapia intensiva e reabilitação. Rio de Janeiro: Guanabara Koogan, 2008, p.1-9.

25. Hall C, Brody LT. Abordagem funcional ao exercício terapêutico para deficiências fisiológicas. Deficiência no desempenho muscular. In: Hall C, Brody LT. Exercício terapêutico: na busca da funçẫo. 2 ed. Rio de Janeiro: Guanabara Koogan, 2007, p. 57-87. 